\title{
Study on Cultivation of Rhetorical and Linguistic Ability of Preschool Children
}

\author{
Yongxin Gao \\ Shaanxi Xueqian Normal University, Shaanxi, Xi’an, China, 710000
}

Keywords: Cultivation, Rhetorical and Linguistic Ability, Preschool Children

\begin{abstract}
The rhetorical language represents a high level of language use and should become an important part of kindergarten language education. Cultivation of the ability of rhetoric language of pre-school children should conform to the rhetoric talent of children and provide appropriate stimulation; it guides the children to analyze the external form of language and the inherent implication of meaning, encourages children to freely use the language and foster children's awareness of language choice. The dual education of concept cognition and rhetorical cognition should be advocated to make it more in line with the natural state of preschool children's cognition. Children's literary creation should be consistent with the pre-school children's rhetorical style and expression characteristics, so as to establish the maximum common semantic field between the author and young readers.
\end{abstract}

\section{Introduction}

Preschoolers often appear with rhetorical language, aroused widespread concern in the field of linguistics, education and other fields, but there is a clear controversy over whether preschool children exist in real rhetorical language. Based on the perspective of pedagogy, based on phenomenological and philosophical thinking and ecological paradigm, this research examines rhetorical language in the overall development of pre-school children and the entire social culture, establishes the combination of qualitative and quantitative analysis, case and group case Research combined with the overall research design to explore the performance of preschool children's rhetoric language, development, production mechanism, influencing factors, values and implications for education [1].

The study found that preschoolers' existence of real rhetorical language is the inevitable result of children's cognitive needs, emotional reminders and social interaction, and is the explicit manifestation of the comprehensive development of children's multiple hidden factors. The pre-school children's rhetoric language is restricted by the national cultural psychology and is shaped and changed by the social and cultural environment that aims at the standard of adults. Rhetorical language development and implementation of two lines, one is on the rise, children's rhetorical awareness increased rhetorical effect; one is a downward trend, children gradually give up their own way of expression, the use of social norms recognized language, deviate from the norms, extraordinary mix of phenomena began cut back.

The use of rhetoric language by preschool children helps to recognize things, stimulate imagination and creativity, expand language experience and create more favorable situations for social development. The pre-school children's rhetoric language has the same function with the whole rhetorical language. It objectively acts as a digging potential language, has special aesthetic and cultural values, and is the source of the entire rhetorical language. Preschool children's rhetoric language is a comprehensive refraction of children's cognition, sociality, emotional development and the whole life. It is homogeneous with the whole development of children, has powerful information functions and productivities, and has distinctive resources for personal development. This shows that language is not only a tool and target for children's learning, but also a resource for the development of preschool children. 


\section{The Value of Preschool Children's Rhetoric Language on Children's Development}

To promote children's understanding of things, provide a vast space of thinking. Establish the relationship between things. Earlier studies suggested that rhetorical language is merely a decoration of language and has no cognitive value. For example, Plato's poetic expression is a distortion of the world. Beginning with Lakoff and Johnson, people began to pay attention to the relationship between figures of speech and cognition such as metaphors. Gibbs.R.W. and other scholars proposed that metaphor is through the analysis of the characteristics of things, similarities between features to establish the relationship between things. Mr. Wang Xi-jie, a famous rhetorician in our country, believes that using metaphor to establish the connection between new and old things makes the system of knowledge formed [2]. This study argues that the universal and common way for mankind to know the world is to expand cognition by using the similarities between new experience and existing experience, from known things to unknown things. Pre-school children through the analysis, analogy, reasoning, association and other psychological processes to establish similarities, establish the relationship between things, metaphor and other rhetorical features of the language of pre-school children's cognitive development of the bridge, the new knowledge into the original cognitive system and enrich and improve the original cognitive system.

Help children understand the characteristics of things. As far as metaphor is concerned, it emphasizes the characteristics of the ontology and the metaphor, emphasizes the message conveyed, and strengthens the children's understanding and memory. Wittgenstein believes that language and the world are intertwined, and metaphor is an important channel to help us understand the world. Ricoeur (1978) argues that linguistic means, like a model, can only show people parts of the world, and metaphors allow people to change these models and thereby change the way people view the world. In other words, metaphor can change people's representation of the world and thus provide people with new information about the world. Preschoolers draw cues from the semantic features they have learned to acquire new perspectives to observe things, name new things, recognize the ontology on the one hand, and at the same time reinforce their understanding of the characteristics of the vehicle. For example, in episode 3 of Topic 1, children with $\mathrm{xx}$ and $\mathrm{xx}$ are twins in charge of all paired pairs and receive new twins continually. This is a speculative inducement based on clear evidence. In the process, children can enrich cognition about correspondence and symmetry.

Expand language experience to provide children with language development orientation. Scholars such as Laura suggested that preschool children would extend the meaning of words by analogy. The rhetoric emerges from the lack of original words, which Fanardier believes are inadequate for us. If the words are as many concepts as possible, our brains simply cannot learn, remember, and use so many words. In general, rhetorical feature language is an important means for children to expand their language experience. Consolidating and strengthening children's cognition of original words and accomplishing the indispensable operating practices in language development, creatively trying to use language to represent things, making pre-school children's expression has a broader space and freedom. Han Iridium proposed that metaphor as a language training game can help people to sum up the initial language knowledge and understanding of the world. - Leaf pages will be trimmed trees haircut to say to the tree, nails nail cut into nails, from passive to ask what they are doing into a proactive expression in the process of extracting the top cut off the meaning of the cut, to strengthen the things feature recognition.

Fully tap the potential of language beauty, stimulate children's beauty. Dr. Chen Rudong suggested that if the metaphor is only regarded as a cognitive pathway, it will lose its original value) rhetoric. Some scholars put forward that the characteristic of literary language lies in the call of association and thought - provoking, because the catharsis of emotion lies in the subtlety and the creation, while the conventional language focuses on the effect of the exchange of information because the obviousness of the meaning lies in its directness is to behave. Rhetoric characteristic language combines the expression of emotion and impulse with the pure cognitive process. Mom, you are my rose garden, my mum like lightning, all of a sudden the rhetorical language passed to vent children's negative emotions, strengthen Positive emotions. According to Mr. Luo Xiaosuo, 
children's rhetorical language truly sublimates the spiritual realm of humanity, purely filled with the spirit and emotion of the subject, embodying the human freedom requirement rather than the limited realistic requirement. Professor Tan Xuechun put forward in broad rhetoric and people enter the aesthetic life through rhetoric. Preschool children also enter the aesthetic life through rhetorical language. Rhetorical language can fully tap the potential of the beauty of language and maximize the beauty of language. Rhetoric is to some extent a product of the game and is the starting point for artistic and scientific creation. Aesthetic factors in the expression of language make aesthetics become an inherent habit of children gradually. Maslow believes that people have their highest degree of identity in the peak experience, closest to their true self, the most specific. Although Maslow did not specialize in children, he said with certainty that children have a peak experience, which is common in childhood. Theme 6 shows many poems created by the leaf pages. Each capital is in one go. The writing process is characterized by high emotion and obvious aesthetic pleasure. The use of rhetorical language, so that children can complete the aesthetic creation in the language, access to spiritual sublimation and in the peak experience state [3].

Improve the quality of language communication, preschool children's social development to provide a more favorable situation. Dumasse, a French rhetorician of the 18th century, argues that rhetoric is more vivid, sublime, and delightful through variation. Feng Zikai had discussed three effects of the metaphor: the first, the meaning can be made concrete; the second, the fact can be exaggerated: thirdly, the language can be made interesting, or the emphasis on a certain aspect or both. The figurative metaphor makes it easy for the listener to understand and exaggerate so that the listener can easily be subtitled and fun to make the listener happy to accept it. Morse and Benze put forward the concept of aesthetic information almost simultaneously at the same time in the 1950s. Ordinary languages are abstract, generalized, rationalized and modeled with the function of expression and reason, while the rhetorical language contains deep Aesthetic information, preservation and evocation of the listener's aesthetic and emotional experience, as more real feelings, can effectively mobilize the senses of the speaker, with the role of passion.

\section{Cultivation of Preschool Children's Rhetorical Language}

On the one hand, pre-school children have the talent to create rhetorical language. Mr. Ye Shengtao affirmed that the child's unsocial instincts are a precious spiritual asset: the children's minds seem to be intuitive, they view everything as containing life, so they often talk with chairs and smile with vegetation. This is the literary view of the universe. If children can express their own intuition, it must be supreme beauty. However, because of actual life, people have eradicated the universalist view of the universe of literary artists, which is ten times as pity as this. Ye Shengtao, literary and art talk, etc. put forward in one hundred languages of children that children are the cultural presenters and creators and implement the basic prerequisites of children's rights. In addition to allowing children to have higher personal civil rights and interpersonal conditions in addition, it must also be acknowledged that each child has an unusually rich, innate natural potential that is both powerful and creative. If these cannot be acknowledged or even lost, they will cause pain to children or even make children often learn irrevocable helplessness. Specifically, implementing the unity of children's rhetorical gifts and providing appropriate stimuli can take the following measures:

First, strengthen children's spontaneous creation of rhetorical language. In the satellite case, Ling Mo about 2 years old felt not enough weight, so to create eight and a lot of two / many say, because adults strengthen eight, so eight took more than six months to disappear; and a Some are not used anymore. Therefore, some scholars believe that adults should be appreciated and strengthened, children will get encouragement and strive to say more such words, make the language more vivid, and adults can also be based on this feature of children, combined with the appreciation of literary works reading, develop children's rich social feelings and beautiful hearts [4].

Second, provide rhetorical language to imitate objects. Mr. Hiran believes that the language ability itself is not desirable, imitation of adults (with the ability to absorb the imitation of things) if you do not play a core role, twelve months to three or four years of language acquisition. We 
provide imitation sentences for children and so on and stimulate the envy of the United States.

Third, use a variety of forms to shape children's language awareness. Language games develop the awareness of children about the language that can be tweaked and correspondingly different. From the birth of more than twenty days, children play the language like toys. Language is an important self-entertainment game for children. - McGhee (1979) Pre-school children often play games and find it playful in speech structures. When children grow older, they noticed that the rhyming of words is interesting. At this time the humor rises to the semantic level. Most occurred in the lower primary school. Hogan (1981) found that some children spontaneously use text jokes or ballads between the ages of 2 and 4 . Ho root that the common language games in the family can improve children's language sense of humor, and thus improve the ability of metaphor. Let children exercise metaphorical sentences, such as pleasure, where the core elements of the activity are imagination, creativity, clever words, and familiar metaphors. Or use metaphor to illustrate things, such as color is, let the children play the phonetic, humorous terms [5].

\section{Conclusions}

The use of rhetorical language on behalf of language is at a high level. The use of rhetoric is beneficial to the development of children's cognition, emotion and aesthetic development. It can also create a more favorable situation for its social development and should be regarded as the target of children's language education The important part (pre-school children have been able to use the real rhetorical language, in order to promote the development of rhetorical skills, teachers should be consistent with children's rhetorical talent and provide appropriate incentives to unify and guide children to analyze the external form of language and feelings of the intrinsic implication unify and encourage children to freely use their language and cultivate them.

\section{Acknowledgements}

Fund Project: Project Fund: Research on the Potential Development of Preschool Children's Rhetoric Language. Item No. SGH13355

\section{References}

[1] Chen Zhang. Research on language resources [J]. Language application. 2008 (01).58.

[2] TAN Xue-Chun. Pragmatic Environment: Information Processing Patterns of Semantic Variation and Cognitive Subject [J]. Journal of Applied Linguistics. 2008 (01).110-112.

[3] SHI Yu-chi. Cyclopsychological evidence of speech synthesis [J]. Language Research. 2007 (03).87-89.

[4] Liu Xiaodong. Children's classics is Mongolia to raise- Discussion with Guo Qijia [J]. Nanjing Normal University (Social Science Edition) .2006 (06).88.

[5] Tan Xuechun, Xiao Li. Chinese language education countermeasures and discourse right in the context of globalization [J]. Application of Linguistic Literatures. 2006 (04).62-63. 